\title{
Control Strategy for the Energy Optimization of Hybrid Regenerative Braking Energy Utilization System Used in Electric Locomotive
}

\author{
Jiande Yan $\mathbb{D}^{1,2}$ Hui Wang, ${ }^{1}$ Shuren Zhong, ${ }^{1}$ Yonghong Lan $\mathbb{D}^{3},{ }^{3}$ and Keyuan Huang ${ }^{1}$ \\ ${ }^{1}$ School of Electrical and Information Engineering, Hunan University, Changsha, Hunan 410082, China \\ ${ }^{2}$ College of Electrical and Information Engineering, Hunan Institute of Engineering, Xiangtan, Hunan 411100, China \\ ${ }^{3}$ School of Information Engineering, Xiangtan University, Xiangtan 411105, Hunan, China \\ Correspondence should be addressed to Jiande Yan; 40334732@qq.com
}

Received 20 September 2018; Revised 13 November 2018; Accepted 28 November 2018; Published 19 December 2018

Guest Editor: Shenping Xiao

Copyright (C) 2018 Jiande Yan et al. This is an open access article distributed under the Creative Commons Attribution License, which permits unrestricted use, distribution, and reproduction in any medium, provided the original work is properly cited.

\begin{abstract}
The braking process of electric locomotive is featured by short braking time, large braking power, large voltage fluctuations, etc. Faced with the problem of low utilization of braking energy and high investment cost of the current regenerative braking energy utilization systems, an energy optimization scheme is proposed in this paper by combining the control strategy for energy storage and energy optimization. The regenerative braking energy utilization system is modeled by analyzing the braking process of electric locomotive. The instantaneous absorption reference powers of the energy storage subsystem and energy feedback subsystem in braking process are obtained according to the established mathematical model. The energy storage subsystem uses super capacitor and adopts a power-current dual closed-loop control strategy. The energy feedback subsystem adopts a voltage-current dual closedloop control strategy. Through the tracking control of the instantaneous power, a reasonable distribution of the regenerative braking energy is achieved between the energy feedback subsystem and energy storage subsystem, thereby increasing the utilization efficiency of the two subsystems. Finally, the performance of the proposed scheme is verified by simulation and experiment.
\end{abstract}

\section{Introduction}

Large amount of regenerative energy is generated in the process of electric locomotive braking. The effective recycling of regenerative energy has many benefits, e.g., stabilizing the bus voltage of traction network, preventing the failure of regenerative braking, and avoiding energy waste [1].

Currently, most of the existing electric locomotive braking systems adopt mechanical contracting brake or consume the regenerative energy on resistance [2]. In comparison, the scheme that absorbs regenerative feedback energy has the advantages of small harmonic content, flexible control strategy, and good dynamic performance. Besides, the system adopting this scheme has a high power factor, which does not change with the change of feedback power, making it a promising choice for the utilization of regenerative energy [3-7]. The braking of electric locomotive is featured by large power and large fluctuation in voltage, which requires that feedback energy system should have high power density and high energy density. However, it is difficult to meet this requirement by a single type of absorption scheme. Super capacitor, with advantages of high power density, long cycle life, good temperature characteristics and simple charging and discharging circuits, is an excellent choice for feedback energy absorption [3, 8-12]. Therefore, the combination of super capacitor and energy-type feedback system provides a promising scheme for the absorption of regenerative feedback energy in electric locomotive braking. Literature [13] proposed a coordinated control of energy storage subsystem (with super capacitors) and energy feedback subsystem to absorb the feedback energy of electric locomotive and to further stabilize the DC bus voltage of traction network. Literature [14] proposed a capacity distribution method for hybrid energy absorption in electric locomotive braking. However, both literature [13] and [14] failed to establish a mathematical model for analyzing the distribution of the 
braking energy between energy storage subsystem and energy feedback subsystem, and their systems both adopted the traditional voltage-current dual closed-loop control strategy. This kind of control strategy mainly aims at suppressing the fluctuation in DC bus voltage and cannot achieve the dynamic tracking control of the feedback power in braking process. Therefore this control strategy fails to achieve an optimal distribution of the feedback energy between energy storage subsystem and energy feedback subsystem.

The contribution of this paper mainly includes the following parts. (1) A mathematical model is established for the regenerative braking energy utilization system. (2) The instantaneous absorption reference powers of the energy storage subsystem and energy feedback subsystem in braking process are obtained according to the mathematical model. (3) An optimized energy distribution scheme that adopts novel control strategies for energy storage subsystem and energy feedback subsystem is proposed, which significantly improves the overall performance of the braking energy utilization system.

The rest of this paper is organized as follows. In Section 2, the mathematical model for the energy storage subsystem and energy feedback subsystem is established and the control strategies for the two subsystems are presented. In Section 3, the energy distribution between the two subsystems and its control strategy are illustrated. In Sections 4 and 5, the simulation and experiment are performed, respectively. Conclusions are drawn in Section 6.

\section{Modeling of Energy Feedback Subsystem and Energy Storage Subsystem}

2.1. The Topology and Control Strategy of Energy Storage Subsystem. The energy storage subsystem consists of two components: the super capacitor bank for storing braking energy and the bidirectional DC-DC converter circuit for charging and discharging the super capacitor bank. The topology and working mode of this subsystem are shown in Figure 1 . The energy storage subsystem receives the charging and discharging commands according to the fluctuation in DC bus voltage. Then the subsystem selects the boost mode or buck mode to suppress the fluctuation of DC bus voltage by absorbing or releasing energy. When electric locomotive is in traction state, the $\mathrm{VT}_{2}$ is turned on with a certain duty cycle, constituting a boost chopper circuit with the antiparallel diode of $\mathrm{VT}_{1}$. As a result, the energy is released to the bus of traction network, at which time $i_{L}$ is negative. When the electric locomotive is in braking state, the $\mathrm{VT}_{1}$ is turned on with a certain duty cycle, constituting a buck chopper circuit with the antiparallel diode of $\mathrm{VT}_{2}$ to absorb the feedback energy from the traction bus, at which time $i_{L}$ is positive.

According to the principle of PWM, we have

$$
U_{S C}=D \cdot U_{d c}
$$

where $U_{S C}$ is the terminal voltage of super capacitor, $D$ is the duty cycle, and $U_{d c}$ is the DC bus voltage.
In steady state, $D=U_{S C} / U_{d c}$ and the voltage of the inductor is zero. The input of the energy storage subsystem is given by [10]

$$
D=\left(\Delta D+D_{s}\right)=\left(U_{L_{S C}}+\frac{U_{S C}}{U_{d c}}\right)
$$

where $U_{L_{S C}}$ is the electromotive force generated by the inductance and $D_{s}$ is the duty cycle in steady state.

The dynamic equations for the inductor/capacitor branch are obtained by Kirchoff's voltage law, as presented by

$$
\frac{d}{d t}\left[\begin{array}{c}
i_{S C} \\
U_{S C}
\end{array}\right]=\left[\begin{array}{cc}
-\frac{R}{L} & -\frac{1}{L} \\
-\frac{1}{C} & 0
\end{array}\right]\left[\begin{array}{c}
i_{S C} \\
U_{S C}
\end{array}\right]+\left[\begin{array}{c}
\frac{1}{L} \\
0
\end{array}\right] U_{d c}
$$

In (3), the system states variables include the voltage $U_{S C}$ generated by the current going through the inductor $i_{L}$ and the capacitor.

Therefore, the dynamics equation of the reduced-order model is obtained and described by

$$
\begin{aligned}
& i_{S C}=-\frac{U_{S C}}{R}+\frac{U_{d c}}{R} \\
& i_{S C}=C \frac{d}{d t} U_{S C}
\end{aligned}
$$

In this research, the energy storage subsystem adopts a dual loop control strategy where the traction bus voltage is the outer loop and the current is the inner loop. Figure 2 shows the control diagram of the energy storage subsystem.

The reference charging current $i_{S C}{ }^{*}$ of the energy storage system is obtained by performing PI operation on the difference between the absorb power $P_{S C}$ and the reference absorption power $P_{S C}{ }^{*}$. Then, the difference between the reference charging current and the measured charging current is adjusted by PI operation, to produce a trigger pulse with the desired duty cycle. The trigger pulse is used to control the turn-on and turn-off of the IGBT.

2.2. The Topology and Control Strategy of Energy Feedback Subsystem. With a power electronics converter, the energy feedback subsystem gives back the braking energy to AC network. The energy feedback subsystem is mainly composed of isolating switch QF, feedback converter and isolated transformer, where the feedback converter is composed of power electronics module, control subsystem, and filter. The main circuit and control diagram of the energy feedback subsystem are shown in Figure 3.

To achieve the decoupled dual closed-loop control of the active and reactive current components in a simple way, the AC-side mathematical model after coordinate transformation is described by [5]

$$
\begin{aligned}
\left(\begin{array}{c}
\frac{d i_{d}}{d t} \\
\frac{d i_{q}}{d t}
\end{array}\right)= & \left(\begin{array}{cc}
-R & \omega L \\
-\omega L & -R
\end{array}\right)\left(\begin{array}{l}
i_{d} \\
i_{q}
\end{array}\right)+\left(\begin{array}{ll}
1 & 0 \\
0 & 1
\end{array}\right)\left(\begin{array}{l}
U_{d} \\
U_{q}
\end{array}\right) \\
& -\left(\begin{array}{ll}
1 & 0 \\
0 & 1
\end{array}\right)\left(\begin{array}{l}
\mathrm{e}_{\mathrm{d}} \\
\mathrm{e}_{\mathrm{q}}
\end{array}\right)
\end{aligned}
$$




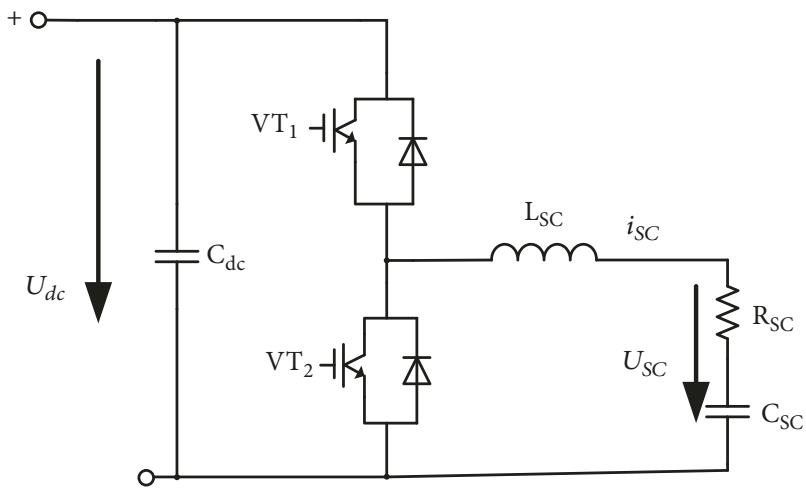

(a) Topology of super capacitor energy storage subsystem

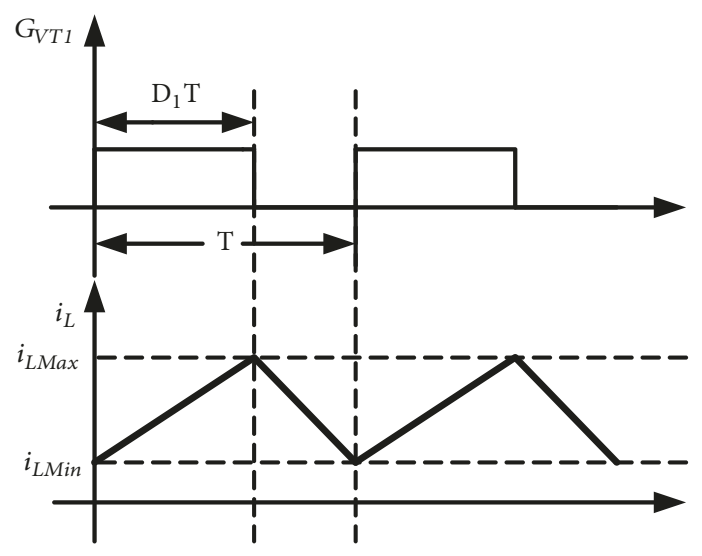

(b) Buck operation mode

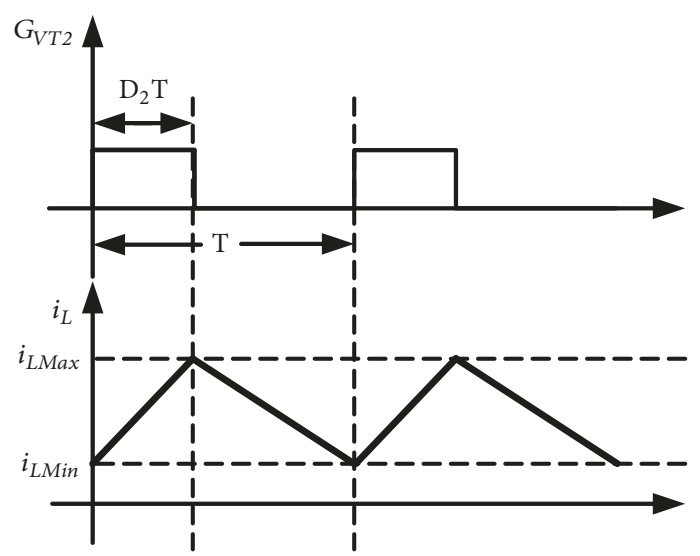

(c) Boost operation mode

FIGURE 1: Topology and working mode of bidirectional DC-DC converter.

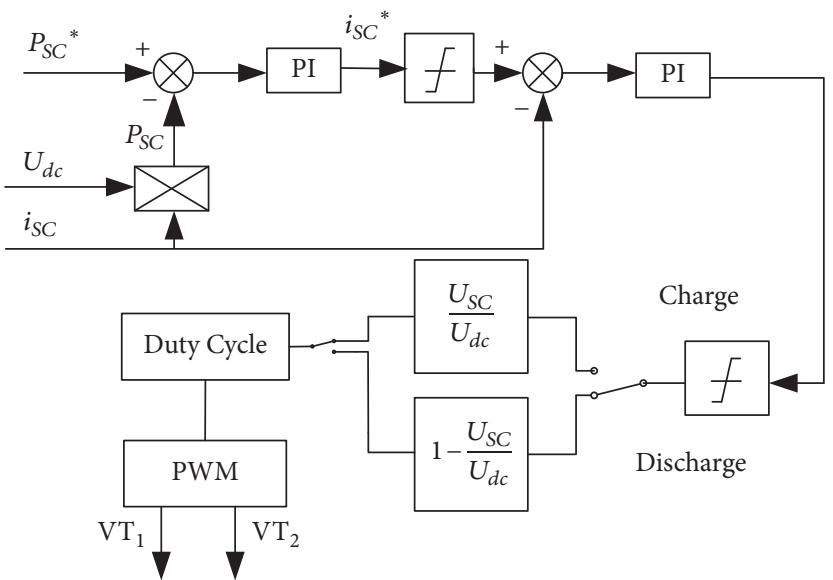

FIGURE 2: Control diagram of the energy storage subsystem.

Thus, the control strategy of the current controller can be obtained by

$$
\begin{aligned}
& U_{d}=-\left(K_{p}+\frac{K_{i}}{S}\right)\left(i_{d}{ }^{*}-i_{d}\right)+\omega L i_{q}+e_{d} \\
& U_{q}=-\left(K_{p}+\frac{K_{i}}{S}\right)\left(i_{q}{ }^{*}-i_{q}\right)-\omega L i_{d}+e_{q}
\end{aligned}
$$

Based on grid-voltage vector orientation, the voltage of AC network in (6) is oriented on the $d$ axis, $e_{d}=0$; when it is in inverter state with negative power factor, the reactive power of the converter is 0 , so the specified reactive current $i_{q}{ }^{*}=0$. The actual DC bus voltage $U_{d c}$ and the given $U_{d c}{ }^{*}$ are used as the input of the PI regulator. The output 


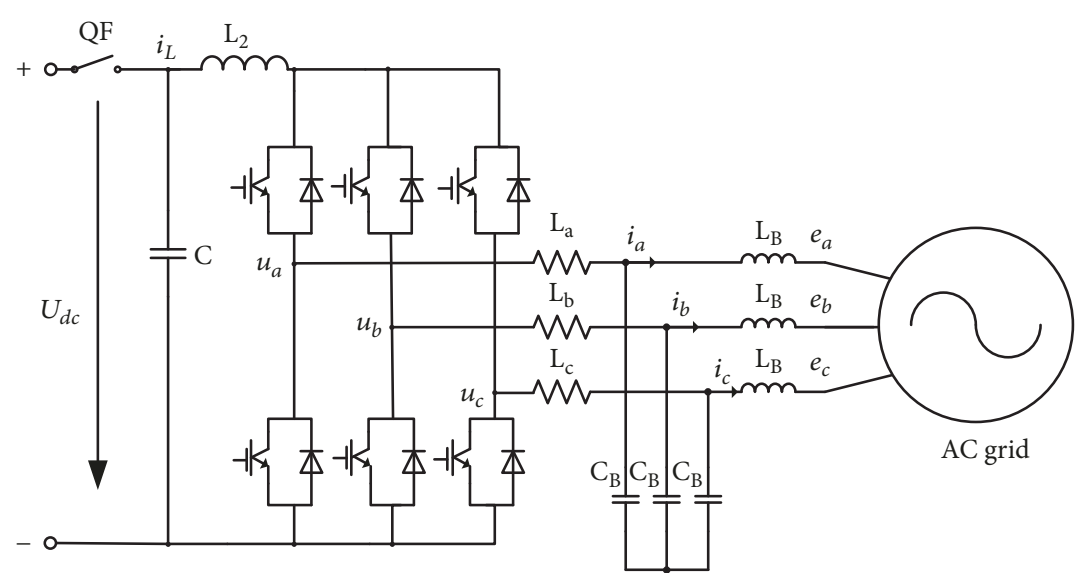

(a) Main circuit of the energy feedback subsystem

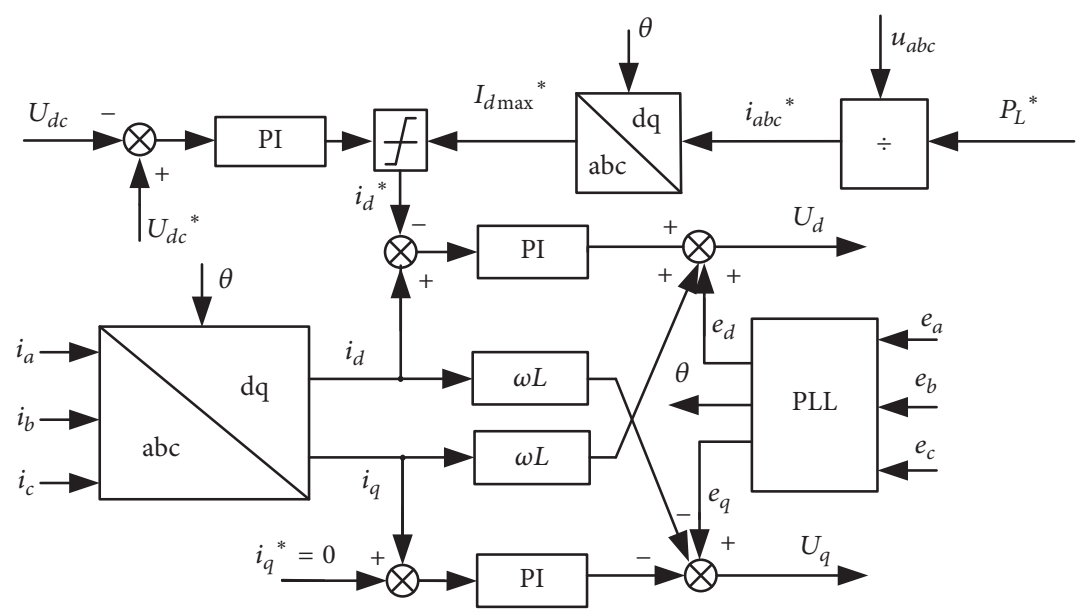

(b) Control diagram of the energy feedback subsystem

FIGURE 3: Main circuit and control diagram of the energy feedback subsystem.

of the PI regulator is used as the reference current $i_{d}{ }^{*}$ of $d$ axis corresponding to the active power. Through adjusting the active power that is given back to the AC network, the increasing speed of the DC bus voltage can be reduced.

\section{Energy Distribution between Energy Feedback Subsystem and Energy Storage Subsystem and Its Control Strategy}

3.1. Theoretical Analysis of the Optimization of Energy Distribution. There are generally two types of control strategies for the distribution of regenerative braking energy between the energy storage subsystem and the energy feedback subsystem, i.e., strategy of energy storage priority and strategy of energy feedback priority. For the purpose of reducing the capacity of the energy storage subsystem and improving the utilization efficiency of the energy feedback subsystem, the strategy of energy feedback priority is selected in this paper. The DC traction buses of the energy storage subsystem and the energy feedback subsystem are parallelly connected.

In the braking process, the speed of electric locomotive is reduced (or the $\mathrm{S}$ curve) with a constant deceleration.
Figure 4 shows the ideal power curve and energy distribution relationship of the two subsystems in the braking process. At the time of $t_{1}$, the electric locomotive enters the braking stage.

It can be seen from Figure 4 that with the increase of the maximum absorption power $P_{L \max }$ of the energy feedback subsystem, the required capacity of the super capacitor is reduced, but the unutilized capacity of the energy feedback subsystem (the corresponding energy is $E_{\Delta L}$ ) is increased. Similarly, as the value of $P_{L \max }$ decreases, although the unutilized capacity of the energy feedback subsystem is reduced, the required capacity of the super capacitor is increased. The goal of the optimization is to maximize the utilization of the energy feedback subsystem and minimize the capacity required for the super capacitor in energy storage subsystem.

To conduct the mathematical modeling, the first step is to obtain the relationship between braking time, initial braking speed, and braking torque by dynamics analysis.

The resistance in the process of electric locomotive braking is composed of basic resistance, electromagnetic braking resistance, and additional air braking resistance. The basic resistance includes bearing resistance, rolling resistance, sliding resistance, shock vibration resistance, and air resistance. 


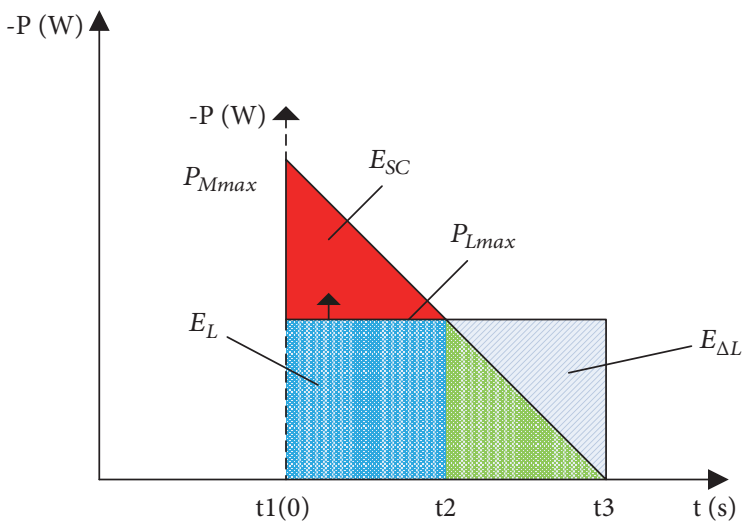

FIGURE 4: Energy distribution between energy feedback subsystem and energy storage subsystem.

The electromagnetic braking resistance is determined by the braking torque and some intrinsic parameters of the electric locomotive.

The basic resistance can be obtained by empirical experiment, which is

$$
F_{w}=\left(a+b v+c v^{2}\right) \cdot M \cdot g \cdot 10^{-3}
$$

where $a, b$, and $c$ are the empirical constants related to the electric locomotive, $M$ is the total mass of the electric locomotive, and $g$ is the gravity coefficient.

The electromagnetic braking resistance is given by

$$
F_{b}=\frac{n_{m a} T_{e} G_{r}}{R_{w} \eta_{g} \eta_{m}}
$$

where $n_{m a}$ is the number of shafts that provide power, $T_{e}$ is the braking torque, $G_{r}$ is the transmission ratio, $R_{w}$ is the wheel radius, $\eta_{g}$ is the efficiency of the gearbox, and $\eta_{m}$ is the efficiency of the motor.

According to the basic law of dynamics, we have

$$
F_{t}=F_{w}+F_{b}+F_{a}=M(1+\gamma) a
$$

where $F_{t}$ is the sum of all resistances in the braking process, $F_{w}$ is the basic resistance, $F_{b}$ is the electromagnetic braking resistance, $F_{a}$ is the air braking resistance, $\gamma$ is the rotary mass coefficient, and $\mathrm{a}$ is the acceleration.

Therefore, the braking time of the electric locomotive can be expressed by

$$
t_{\text {break }}=t_{3}-t_{1}=\frac{v}{a}
$$

Bringing (7), (8), and (9) into (10), the braking time can be calculated by

$$
\begin{aligned}
& t_{\text {break }} \\
& =\frac{\mathrm{V}_{s} \mathrm{M}(1+\gamma)}{\left(\mathrm{a}+\mathrm{bv}+\mathrm{cv}^{2}\right) \cdot \mathrm{M} \cdot \mathrm{g} \cdot 10^{-3}+n_{m a} T_{e} G_{r} / R_{w} \eta_{g} \eta_{m}+F_{a}} \\
& =\frac{\mathrm{V}_{s} M(1+\gamma)}{C}
\end{aligned}
$$

where $V_{s}$ is the speed of the electric locomotive when entering the braking stage and $C$ is the equivalent constant resistance in the braking process.

For the convenience of modeling, the $x$ axis in Figure 4 is translated to the position of the $t_{1}$ moment in the original coordinate system. In the new coordinate system, the feedback power in the braking process is given by

$$
p_{M}=P_{M \max }\left(1-\frac{t}{t_{3}}\right)=P_{M \max }\left(1-\frac{t}{t_{\text {break }}}\right)
$$

where $p_{M}$ is the instantaneous feedback power in the braking process, $P_{M \max }$ is the peak feedback power in the braking process, and $t_{\text {break }}$ is the braking time in (11).

Then, the $t_{2}$ moment, i.e., the intersection of the feedback power curve and the maximum absorption power of the energy feedback system (the energy storage subsystem changes from absorbing power to releasing power), can be calculated by

$$
t_{2}=\left(1-\frac{P_{L \max }}{P_{M \max }}\right) t_{3}=\left(1-\frac{P_{L \max }}{P_{M \max }}\right) t_{\text {break }}
$$

where $P_{L \max }$ is the maximum absorption power of the energy feedback subsystem.

Further, the energy absorbed by the energy storage subsystem and the energy absorbed by the energy feedback subsystem are calculated by

$$
\begin{aligned}
& E_{S C}=\frac{1}{2} \frac{\left(P_{M \max }-P_{L \max }\right)^{2}}{P_{M \max }} t_{\text {break }} \\
& E_{\Delta L}=\frac{1}{2} \frac{P_{L \max }^{2}}{P_{M \max }} t_{\text {break }}
\end{aligned}
$$

The super capacitors in the system require a large-scale combination of series and parallel work, and their overall performance will decrease depending on many factors such as temperature, bias voltage, and inconsistent monomer parameters [15]. The cost of absorbing the same amount of energy varies for energy storage subsystem and energy 
feedback subsystem. So a parameter $\lambda$ is introduced to act as the ratio of unit cost, which is defined by

$$
\lambda=\frac{C_{\text {cost }}}{P \cdot T_{\text {life }}}
$$

where $P$ is the power of the system, $T_{\text {life }}$ is the service life of the system, and $C_{\text {cost }}$ is the total cost of the system.

To optimize the system, an objective function is defined as

$$
S=\lambda_{S C} E_{S C}+\lambda_{L} E_{L}
$$

where $\lambda_{S C}$ is the ratio of unit cost energy ratio of energy storage subsystem, $\lambda_{L}$ is the ratio of unit cost energy ratio of energy feedback subsystem, $E_{S C}$ is the energy absorbed by energy storage subsystem, and $E_{L}$ is the energy fed back by energy feedback subsystem.

When $S$ in (17) reaches the minimum, an optimal distribution is achieved between energy storage subsystem and energy feedback subsystem. Bringing (14) and (15) into (17), we have

$$
S=\frac{1}{2} \lambda_{S C} \frac{P_{L \max }^{2}}{P_{M \max }} t_{3}+\frac{1}{2} \lambda_{L} \frac{\left(P_{M \max }-P_{L \max }\right)^{2}}{P_{M \max }} t_{3}
$$

To find the minimum of $S$, we let

$$
\frac{\partial S}{\partial P_{L \max }}=0
$$

Therefore, the maximum absorption power of the energy feedback subsystem is obtained as

$$
P_{L \max }=\frac{\lambda_{L}}{\lambda_{S C}+\lambda_{L}} P_{M \max }
$$

Correspondingly, the instantaneous absorption power of the energy feedback subsystem and that of the energy storage subsystem can be obtained as

$$
\begin{aligned}
p_{L}{ }^{*} & =\frac{\lambda_{L}}{\lambda_{S C}+\lambda_{L}} P_{M \max }, \quad 0<\mathrm{t} \leq \mathrm{t}_{2} \\
p_{L}{ }^{*} & =P_{M \max }\left(1-\frac{t}{t_{3}}\right), \quad \mathrm{t}_{2}<t<t_{3} \\
p_{S C}{ }^{*} & =\left(\frac{\lambda_{S C}}{\lambda_{S C}+\lambda_{L}}-\frac{t}{t_{3}}\right) P_{M \max }, \quad 0<\mathrm{t} \leq \mathrm{t}_{2} \\
P_{S C}{ }^{*} & =0, \quad \mathrm{t}_{2}<t<t_{3}
\end{aligned}
$$

where $p_{L}{ }^{*}$ is the instantaneous absorption power of the energy feedback subsystem and $p_{S C}{ }^{*}$ is the instantaneous absorption power of the energy storage subsystem.

\subsection{Control Strategy for the Optimal Distribution of Braking} Energy. The control strategy in this research aims at controlling the feedback power of electric locomotive and the fluctuation in the DC bus voltage of traction network. This paper researches the master-slave control strategy combining energy storage and energy feedback. Specifically, the main controller distributes the absorption power of the energy storage subsystem and the energy feedback subsystem based on the DC bus voltage of traction network. The control diagram of the proposed energy distribution scheme is shown in Figure 5. In the figure, the absorption power is calculated based on the fluctuation in the DC bus voltage and then the command is transmitted to the energy feedback subsystem and the energy storage subsystem. The energy storage subsystem independently suppresses the fluctuation of the DC bus voltage in traction network.

The energy storage subsystem adopts the dual closedloop control strategy with active power and current. The reference power absorbed by the super capacitor can be obtained by (22). The difference between the reference power and the actual power is adjusted by PI operation to obtain the reference charging and discharging currents of the super capacitor. The reference current and the actual current are adjusted by PI operation to formulate a pulse with desired duty cycle. The energy feedback subsystem adopts the dual closed-loop control strategy with bus voltage and current as the parameters. The maximum absorption power of the energy feedback subsystem can be obtained by (21), to further obtain the three-phase current of the energy feedback subsystem. The corresponding maximum active current component (negative value) can be obtained by the Park transform. Thus, the maximum absorption power of the energy feedback subsystem can be suppressed by limiting the maximum active component of the energy feedback subsystem.

In the braking stage, the distribution of feedback energy is as follows

$$
\begin{aligned}
E_{M} & =\int P_{M} d t \\
E_{S C} & =\int P_{S C} d t=\int i_{S C} u_{S C} d t \\
E_{L} & =\int P_{L} d t=3 \int u_{L} i_{L} d t
\end{aligned}
$$

where $E_{M}$ is the energy generated by the electric locomotive braking, $E_{S C}$ is the energy absorbed by the energy storage subsystem, and $E_{L}$ is the energy absorbed by the energy feedback subsystem.

To verify the effectiveness of the proposed energy distribution scheme, we let

$$
\begin{aligned}
a & =\frac{E_{S C}}{E_{M}} \\
b & =\frac{P_{L \max }}{P_{\text {Mmax }}} \\
\gamma & =\frac{E_{L}}{E_{L}+E_{\Delta L}}=\frac{E_{L}}{P_{L \max } \times t_{3}} \\
\eta & =\frac{E_{S C}+E_{L}}{E_{M}} \times 100 \%
\end{aligned}
$$

where $\alpha$ is the ratio of the energy absorbed by the super capacitor to the total feedback energy, $\beta$ is the ratio of the 


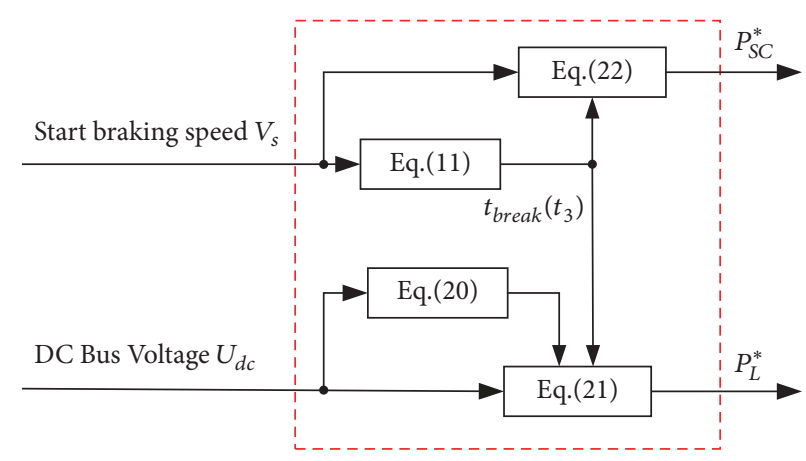

FIgURE 5: Control diagram of the energy distribution scheme.

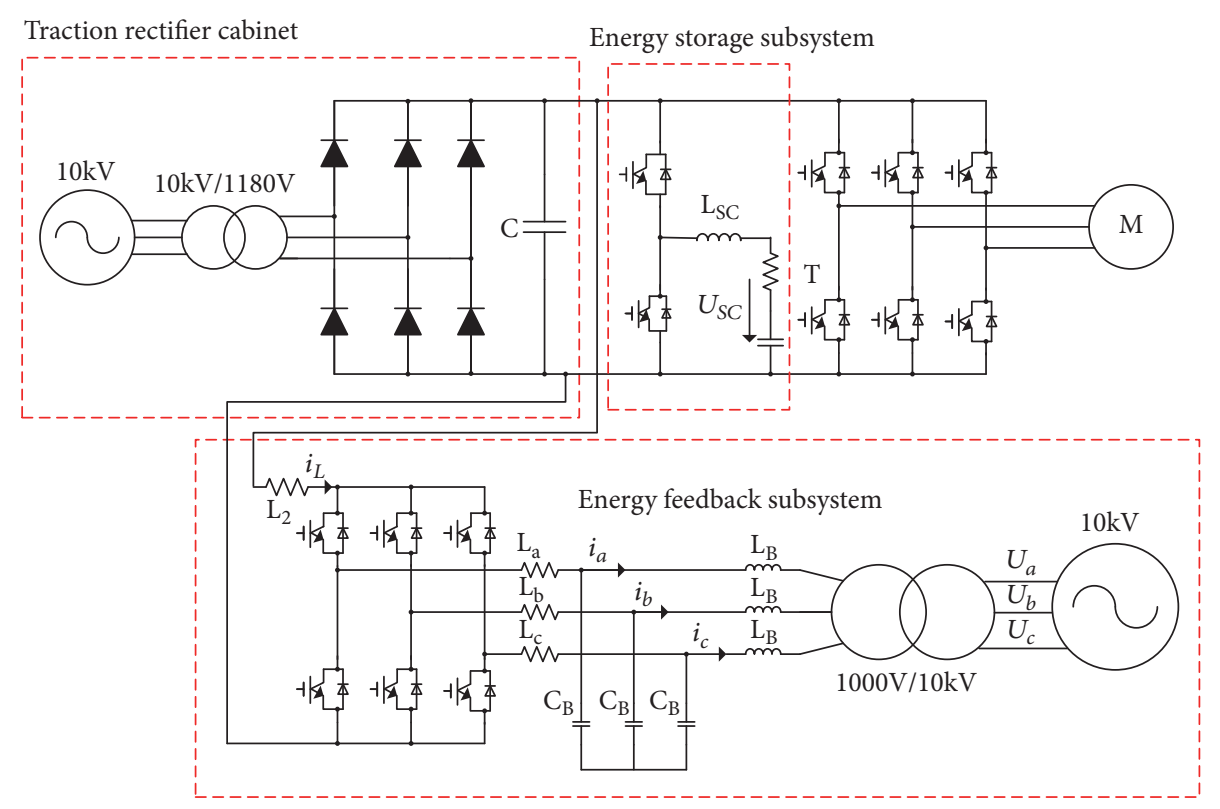

FIGURE 6: Main circuit topology of hybrid braking energy utilization system in electric locomotive.

capacity of the converter in the energy feedback subsystem to the peak power of the electric locomotive braking, $\gamma$ is the efficiency of the converter in the energy feedback subsystem, and $\eta$ is the efficiency of absorbing regenerative feedback energy.

\section{Simulation Analysis}

To evaluate the effectiveness of the proposed energy distribution scheme and the control strategy, MATLAB/Simulink platform is used to construct the model of regenerative braking energy utilization system. Figure 6 shows the modeled system which is mainly composed of three modules, i.e., traction substation, energy storage subsystem, and energy feedback subsystem. The AC voltage of $10 \mathrm{kV}$ is reduced by the traction substation and rectified by 24-pulse wave, to obtain the DC bus voltage of traction network, $1500 \mathrm{~V}$, for electric locomotive traction. The electric locomotive adopts the Atype model with 6 tractors and 2 trailers. Each tractor is driven by six AC asynchronous motors.
TABLE 1: Parameters of electric locomotive system.

\begin{tabular}{lc}
\hline Parameter & Value \\
\hline Model of traction motor & 1 TB2010 \\
Electric locomotive mass $(\mathrm{M} / \mathrm{t})$ & 225 \\
Rated power $(\mathrm{P} / \mathrm{MW})$ & 4.56 \\
Max running speed $(\mathrm{km} / \mathrm{h})$ & 80 \\
Rated voltage of traction network $(\mathrm{U} / \mathrm{V})$ & 1500 \\
Wheel radius $(\mathrm{R} / \mathrm{m})$ & 0.4025 \\
Motor efficiency & 0.9 \\
Gearbox efficiency & 0.96 \\
Max braking force $(\mathrm{F} / \mathrm{kN})$ & 342.24 \\
\hline
\end{tabular}

Tables 1 and 2 show the parameters of the electric locomotive system and the super capacitor bank, respectively.

The main parameters of the simulation model are as follows: DC bus voltage of traction network $U_{d c}=1500 \mathrm{~V}, L_{S C}$ $=0.012 \mathrm{H}$, super capacitor voltage $U_{S C \min }=750 \mathrm{~V}$ and $U_{S C \max }$ 

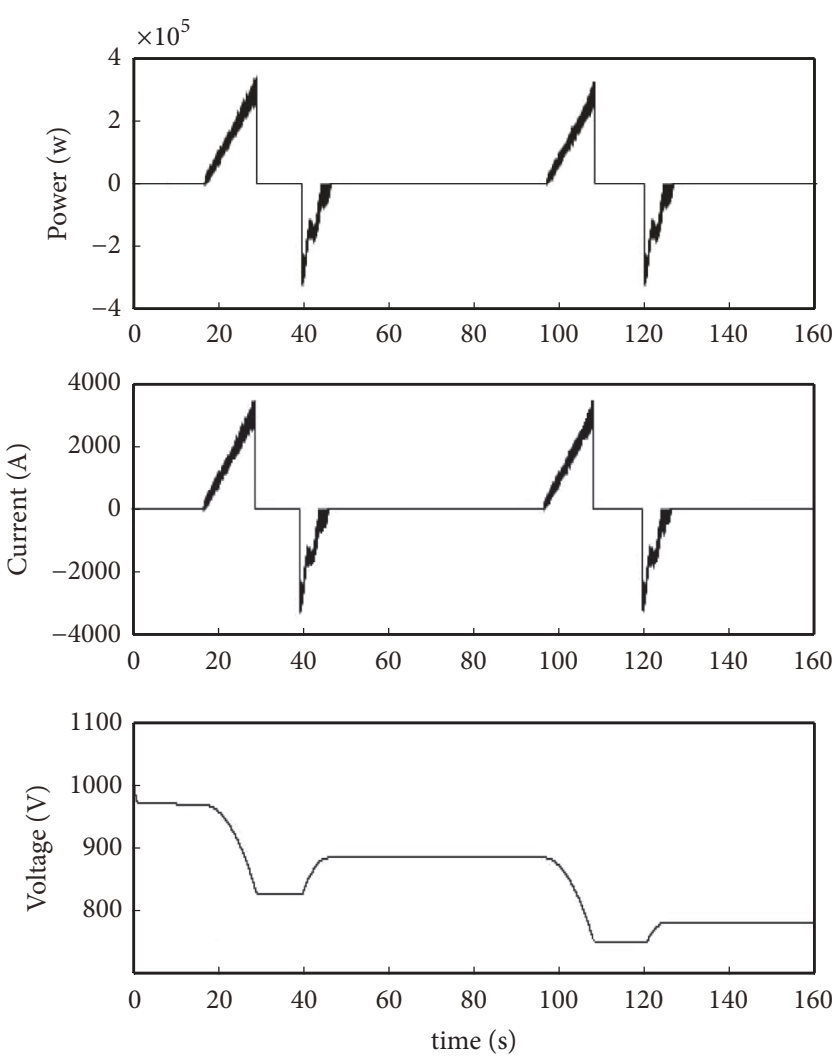

FiguRE 7: Working characteristics of the energy storage subsystem.
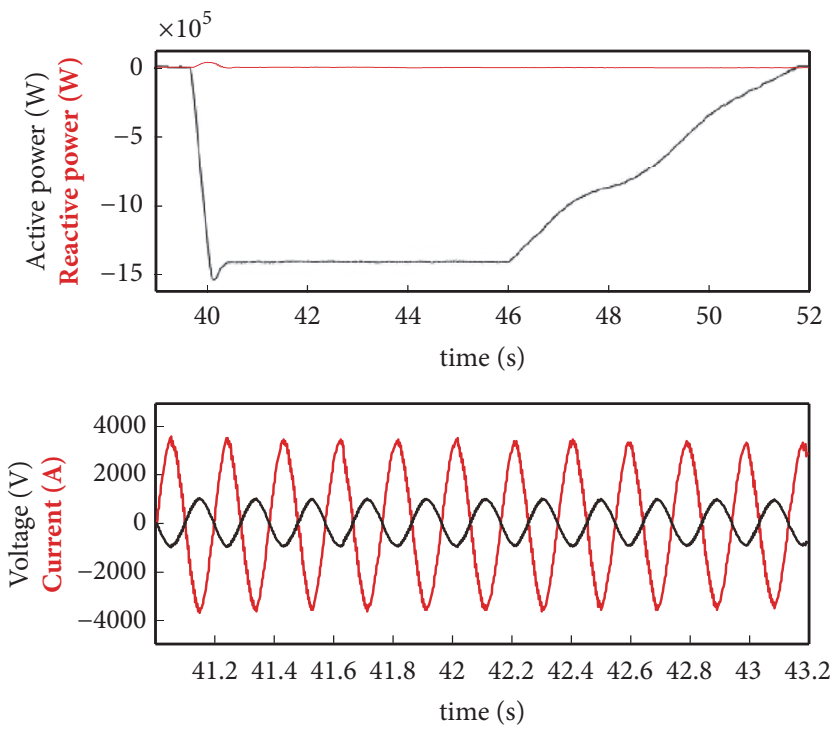

FIGURE 8: Working characteristics of the energy feedback subsystem.

$=1000 \mathrm{~V}$, energy storage capacity $C=24 \mathrm{~F}$, internal resistance $R_{\mathrm{SC}}=5.6 \mathrm{~m} \Omega$, switching frequency of IGBT is $5000 \mathrm{~Hz}$, and the maximum feedback power of energy feedback system is 1.5MW. The simulation results are presented in Figures 7-10.

Figure 7 shows the working characteristics of the energy storage subsystem. At $t=20 \mathrm{~s}$, when the DC bus voltage is lower than $1450 \mathrm{~V}$, the energy storage subsystem enters the discharging mode, and the DC bus voltage is stabilized by releasing the energy in energy storage subsystem, with peak discharging current of about 3200A. At $t=30 \mathrm{~s}$, the starting stage comes to an end and the energy storage subsystem enters a stable state, neither releasing nor absorbing energy. At $t=40 \mathrm{~s}$, the electric locomotive enters the braking stage, and the regenerative braking energy released to the traction 


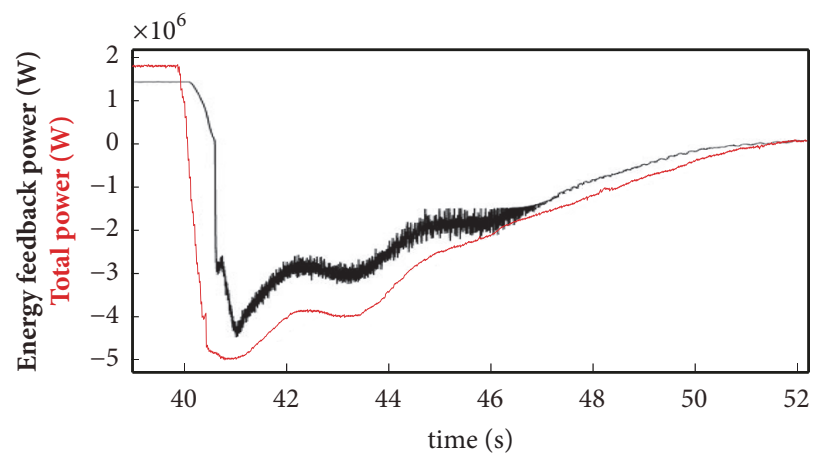

FIGURE 9: Energy cycling status during electric locomotive braking.
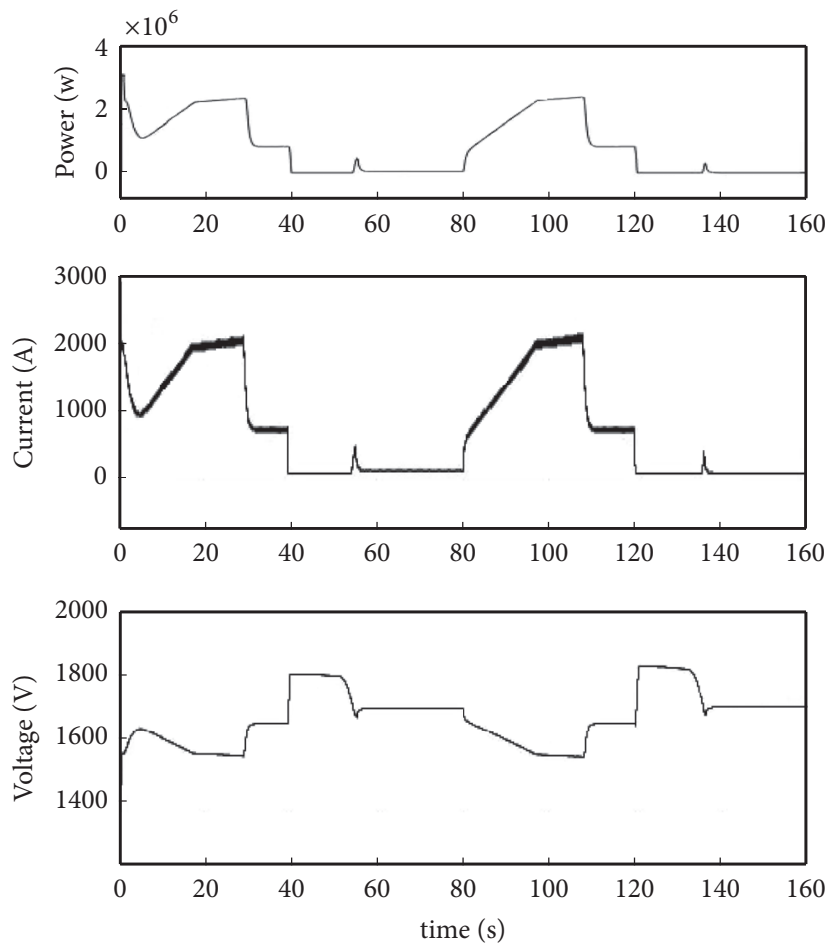

FIGURE 10: Working characteristics of the DC bus voltage.

TABlE 2: Parameters of the super capacitor.

\begin{tabular}{lc}
\hline Parameter & Value \\
\hline Single unit & $3000 \mathrm{~F}, V_{\max }=2.5 \mathrm{~V}$ \\
Energy density $(\mathrm{Wh} / \mathrm{kg})$ & 6 \\
Combination of series and & 4 parallel $\times 500$ series, $24 \mathrm{~F}$ \\
parallel connection & 5.2 \\
Available energy $(\mathrm{kW} \cdot \mathrm{h})$ & 1250 \\
Max voltage $(\mathrm{V})$ &
\end{tabular}

network causes an increase in the DC bus voltage; the energy storage subsystem enters the charging mode and stabilizes the DC bus voltage at around $1800 \mathrm{~V}$ by absorbing excess regenerative feedback energy; the peak of charging current reaches $3000 \mathrm{~A}$ and the maximum power released and absorbed by the energy storage subsystem is both about $3 \mathrm{MW}$, with the super capacitor voltage fluctuating between $750 \mathrm{~V}$ and $1000 \mathrm{~V}$

Figure 8 shows the working characteristics of the energy feedback subsystem. In the stage of starting and the stage of moving at constant speed, the energy feedback subsystem does not work. When the electric locomotive enters the braking stage, the energy feedback subsystem begins to absorb the braking energy with a maximum power of $1.5 \mathrm{MW}$, and the excess braking energy is absorbed by the energy storage subsystem. When the braking energy is less than the maximum absorption energy of the energy feedback subsystem, the energy storage subsystem stops working, and the energy feedback subsystem absorbs all of the regenerative feedback energy. In the braking stage, the energy feedback subsystem always absorbs the regenerative feedback energy with a negative power factor, a voltage amplitude of $1000 \mathrm{~V}$, and a current amplitude of 3200A. 


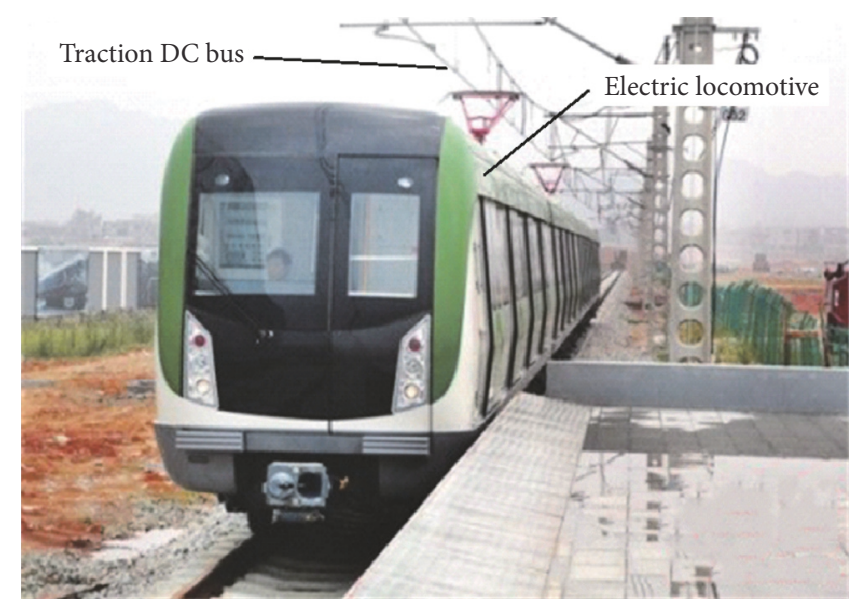

(a) Experiment system platform

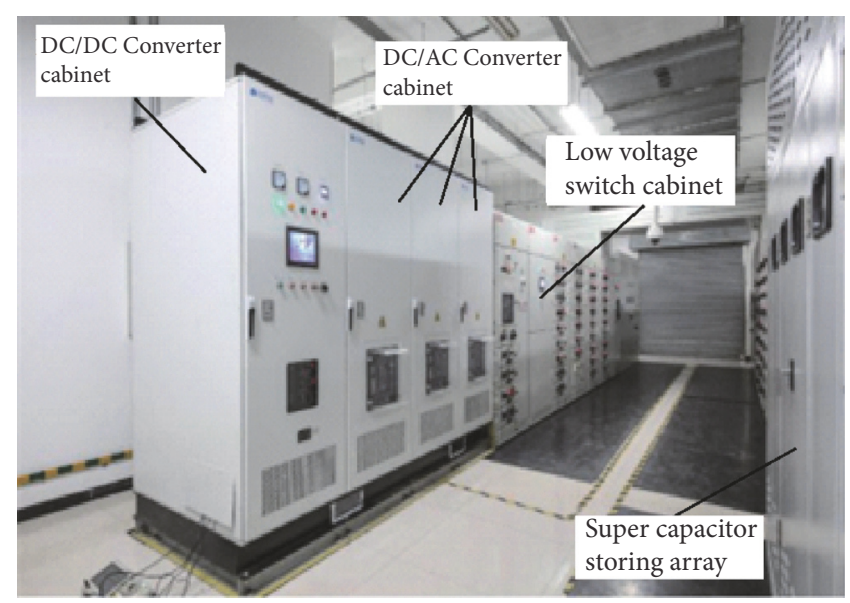

(b) Energy utilization system

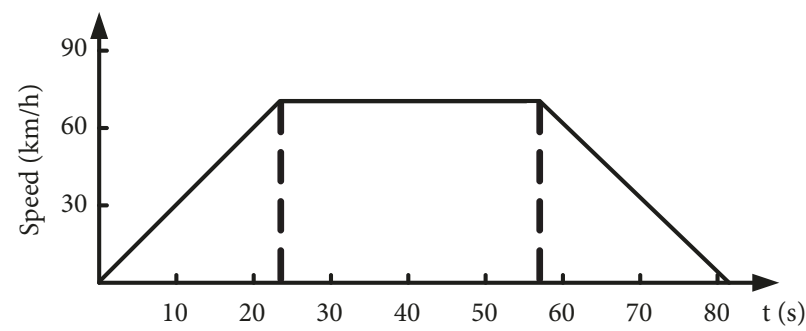

(c) Electric locomotive operation characteristic curve

FiguRE 11: Facilities for field experiment and the working characteristics of the electric locomotive.

Figure 9 shows the energy recycling status in the process of electric locomotive braking. The peak power of the feedback energy is about 5MW. The peak power absorbed by the regenerative braking energy utilization subsystem is about 4.5 MW. According to Figure 9 and (23), the total braking energy generated by the electric locomotive and the energy absorbed by the absorption subsystem are $E_{M}=8.1 \mathrm{~kW} \cdot \mathrm{h}, E_{S C}=2.5 \mathrm{~kW} \cdot \mathrm{h}$, and $E_{L}=4.2 \mathrm{~kW} \cdot \mathrm{h}$, respectively, where the unabsorbed energy of $1.4 \mathrm{~kW} \cdot \mathrm{h}$ is the sum of the switching loss and resistance loss of the power electronics device. It can be known from (20) and Figure 10 that the energy absorbed by the super capacitor is only 0.31 times of the total feedback energy, which greatly reduces the capacity of the energy storage subsystem; that the maximum absorption power of the energy feedback subsystem is 0.3 times of the peak power in braking process, with the utilization of the converter capacity being $81 \%$; and that the recycling rate of the regenerative braking energy is as high as $82.7 \%$.

Figure 10 shows the working characteristics of the DC bus voltage. In the stage of electric locomotive starting, the traction substation transmits power to the electric locomotive through the DC bus. The transmitted power gradually increases in the early stage of starting and becomes stable at around 3.2 MW in the late stage of starting. When entering the braking stage, due to the clamping function of the rectifier diode, the regenerative energy cannot flow to the traction substation, and the power transmitted by the traction bus is zero. The simulation result shows that energy storage subsystem effectively suppresses the decrease of the DC bus voltage during starting stage, and the DC bus voltage is maintained at a preset value of $1450 \mathrm{~V}$. During braking stage, the DC bus voltage does not exceed $1800 \mathrm{~V}$ due to the functioning of the energy feedback subsystem and the energy storage subsystem. Since the fluctuation in the DC bus voltage is within a reasonable range, the current curve of the DC bus is similar to its power curve.

\section{Field Experiment}

To verify the performance of the proposed scheme, the field experiment was carried out using the electric locomotive and other facilities from Zhuzhou CRRC Times Electric Co., Ltd. The parameters of the electric locomotive and the facilities are shown in Tables 1 and 2. Figure 11 shows the experimental facilities and the electric locomotive's working characteristics. As can be seen from the figure, the electric locomotive experiences the stage of staring (0-23 s), the stage of moving at constant speed (23-57 s), and the stage of braking (57-81 s).

The experimental results are shown in Figures 12 and 13. Figure 12 shows the curves of the DC bus voltage of traction network $\left(U_{d c}\right)$, the power of the super capacitor $\left(P_{s c}\right)$, and the voltage of the super capacitor $\left(U_{s c}\right)$. Figure 13 shows the curves of energy feedback power $\left(P_{L}\right)$, the working current $\left(i_{L}\right)$, and the feedback power of electric locomotive $\left(P_{M}\right)$. The no-load voltage of the DC bus is $1500 \mathrm{~V}$.

In the stage of starting, the starting power supplied by the traction substation to the electric locomotive flowed through the line impedance, causing a decrease in the DC bus voltage. 


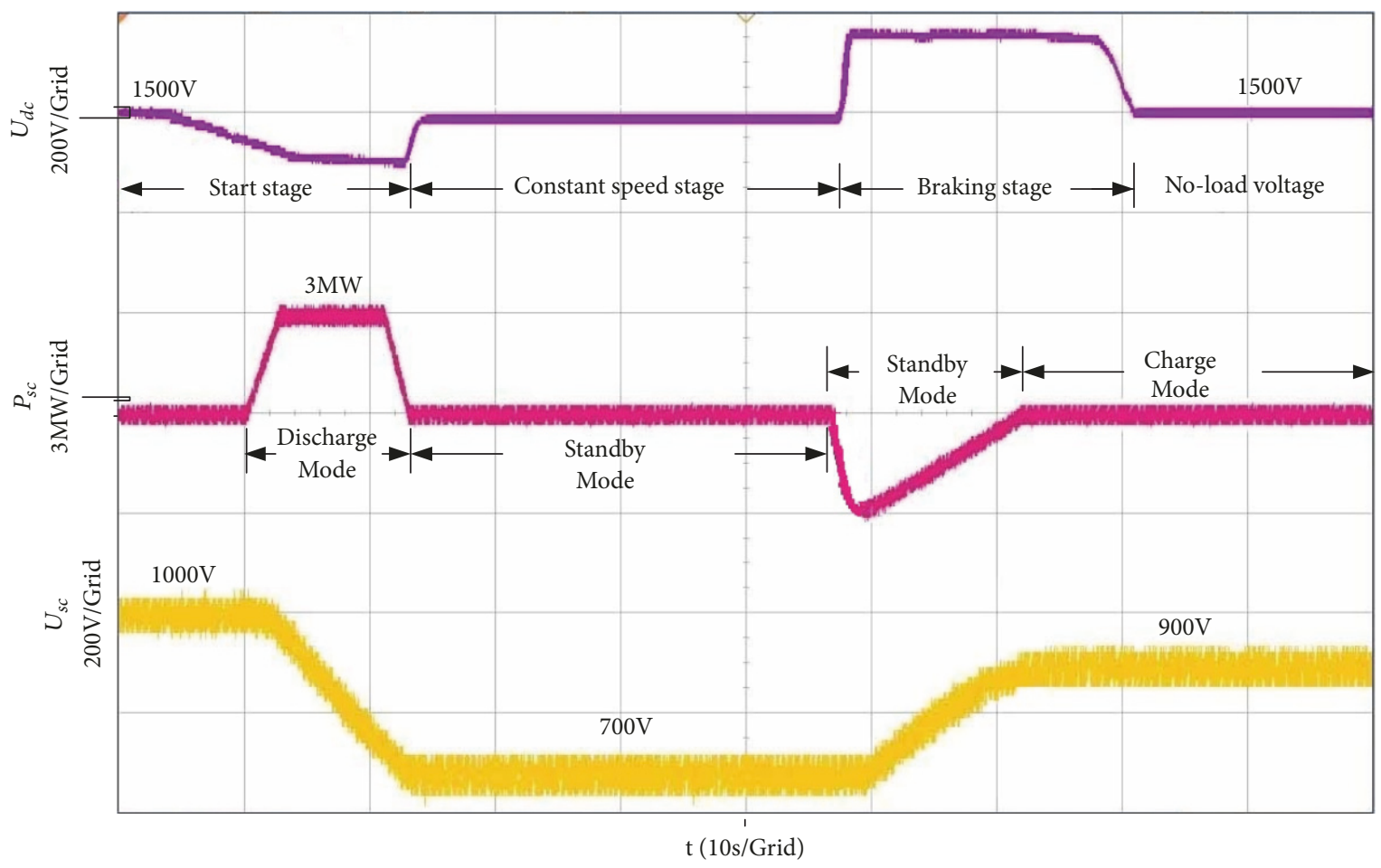

FIGURE 12: Results of field experiment: bus voltage $U_{d c}$, super capacitor power $P_{s c}$, and super capacitor voltage $U_{s c}$.

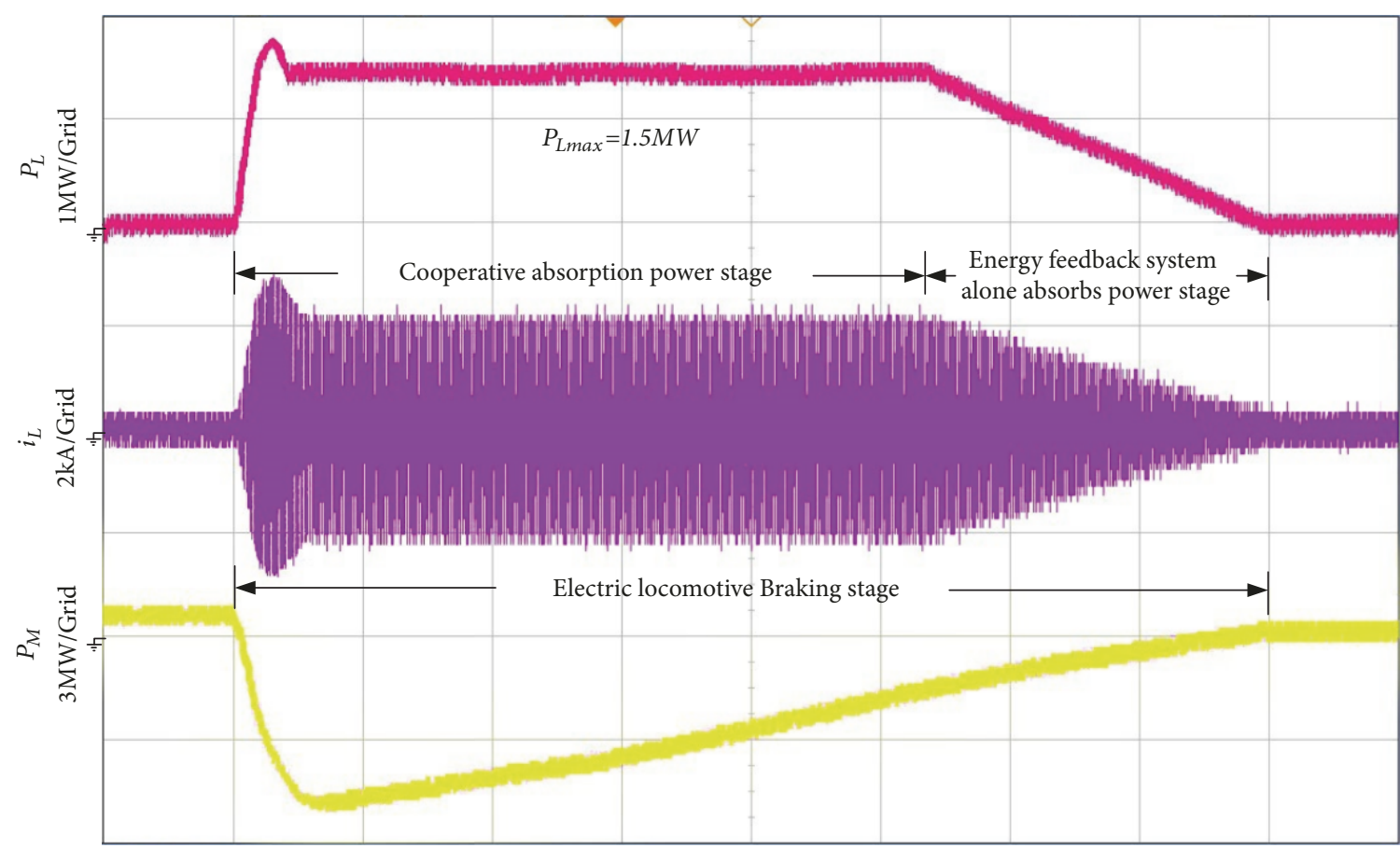

t (3s/Grid)

Figure 13: Results of field experiment: energy feedback subsystem power $P_{L}$, energy feedback subsystem current $i_{L}$, and electric locomotive feedback power $P_{M}$. 
To prevent the huge decrease in bus voltage, the energy storage subsystem released energy to the DC bus with a peak power of 3MW. The DC bus voltage was finally stabilized at about $1400 \mathrm{~V}$, and the super capacitor voltage was reduced from $1000 \mathrm{~V}$ to $700 \mathrm{~V}$. In the stage of moving at a constant speed, the operating power of the electric locomotive was low, the DC bus voltage was approximately restored to $1500 \mathrm{~V}$, the energy storage subsystem entered the standby mode, and super capacitor voltage remained constant at $700 \mathrm{~V}$. When entering the braking stage, the regenerative feedback energy was charged to the DC bus, causing the bus voltage to rise beyond the preset value, and the energy storage subsystem was switched from standby mode to charging mode. At the same time, the energy feedback subsystem received the command to start its operation.

It can be seen from Figure 13 that the peak power of the electric locomotive braking was $5 \mathrm{MW}$, and the generated feedback energy generated was about $16.7 \mathrm{~kW} \cdot \mathrm{h}$. For the synergistic absorption of feedback energy in the early stage, the peak power of the energy storage subsystem was $3 \mathrm{MW}$, and the absorbed feedback energy was about $6.2 \mathrm{~kW} \cdot \mathrm{h}$. The energy feedback subsystem always absorbed the feedback energy with the maximum absorption power of $1.5 \mathrm{MW}$, the absorbed feedback energy was $6.6 \mathrm{~kW} \cdot \mathrm{h}$, and the bus voltage was stable at $1700 \mathrm{~V}$. In the final stage, with the decrease of feedback energy, the energy storage subsystem stopped its operation, and only the energy feedback subsystem absorbed all the feedback energy of $1.67 \mathrm{~kW} \cdot \mathrm{h}$, and the braking process ended. From (24), $\alpha$ is calculated as 0.3 and $\beta$ as 0.371 .

\section{Conclusions}

This paper proposes an optimized scheme for the reasonable energy distribution between energy storage subsystem and energy feedback subsystem. This scheme adopts an improved voltage-current dual closed-loop control strategy. The experimental results show that the maximum absorption power of the energy feedback subsystem is 0.3 times of the peak power of the electric locomotive braking, with a capacity utilization efficiency of $81 \%$ and that the energy absorbed by the energy storage subsystem is 0.371 times of the energy of electric locomotive braking. The fluctuation in the DC bus voltage of traction network and the recycling rate of the regenerative braking energy are within the normal range. It is verified by the simulation and experiment that the proposed scheme can effectively overcome the shortcomings of low energy density of energy storage subsystem and weak antishock power of energy feedback subsystem. The proposed scheme has improved the capacity utilization of the energy feedback devices and shows good economic benefits.

\section{Data Availability}

The data used to support the findings of this study are available from the corresponding author upon request.

\section{Conflicts of Interest}

The authors declare that they have no conflicts of interest.

\section{Acknowledgments}

This research is financially supported by the Science and Technology Research Project for Strategic Emerging Industry of Hunan Province (No. 2016GK4027) and the National Natural Science Foundation of China (No. 61573298).

\section{References}

[1] Y. Kuang, Y. Zhang, B. Zhou et al., "A review of renewable energy utilization in islands," Renewable \& Sustainable Energy Reviews, vol. 59, pp. 504-513, 2016.

[2] JiangJun, "Comparison and analysis of transit train regenerative braking energy utilization system solutions," Modern Urban Transit, vol. 9, no. 1, 2017.

[3] Z. Yang, Z. Yang, H. Xia, and F. Lin, "Brake Voltage Following Control of Supercapacitor-Based Energy Storage Systems in Metro Considering Train Operation State," IEEE Transactions on Industrial Electronics, vol. 65, no. 8, pp. 6751-6761, 2018.

[4] M. Popescu, A. Bitoleanu, I. Deaconu, and M. Dobriceanu, "Improvement of power quality and energy efficiency in bucharest metro traction substations," in Proceedings of the 17th IEEE International Power Electronics and Motion Control Conference, PEMC 2016, pp. 906-911, Bulgaria, September 2016.

[5] Y. Yong, F. Gang, L. Jinjun, Jiangfeng, and L. Tao, "A virtual $\mathrm{RC}$ active damping method in weak grid for three-level threephase grid-connected inverters," in Proceedings of the 8th IEEE International Power Electronics and Motion Control Conference, IPEMC-ECCE Asia 2016, pp. 741-747, China, May 2016.

[6] Z. Ruiqiu, B. Daqiang, and G. Baoming, "Application of Regenerative Braking Energy Injected-grid Device for Subway," Power Electronics, vol. 46, no. 9, p. 61, 2012.

[7] L. Wang, G. Zhang, M. Shen, H. Quan, and Z. Liu, "A novel traction supply system for urban rail transportation with bidirectional power flow and based on PWM rectifier," in Proceedings of the International Conference on Energy and Environment Technology (ICEET '09), pp. 40-43, October 2009.

[8] S. K. Kollimalla, M. K. Mishra, and N. L. Narasamma, “Design and analysis of novel control strategy for battery and supercapacitor storage system," IEEE Transactions on Sustainable Energy, vol. 5, no. 4, pp. 1137-1144, 2014.

[9] H. Xia, Z. Yang, Z. Yang, F. Lin, and X. Li, "Control Strategy of Supercapacitor Energy Storage System for Urban Rail Transit Based on Operating Status of Trains," Diangong Jishu Xuebao/Transactions of China Electrotechnical Society, vol. 32, no. 21, pp. 16-23, 2017.

[10] A. Adib and R. Dhaouadi, "Modeling and analysis of a regenerative braking system with a battery-supercapacitor energy storage," in Proceedings of the 7th International Conference on Modeling, Simulation, and Applied Optimization, ICMSAO 2017, UAE, April 2017.

[11] E. Chen, B. Bu, and S. Wenzhe, "An Energy-Efficient Operation Approach Based on the Utilization of Regenerative Braking Energy among Trains," in Proceedings of the 18th IEEE International Conference on Intelligent Transportation Systems, ITSC 2015, pp. 2606-2611, Spain, September 2015.

[12] H. Chen, H. Xia, Z. Yang, and X. Li, "Study of output impedance optimization for stationary super-capacitor energy storage applied in urban rail power supply system," in Proceedings of the 54th Annual Conference of the Society of Instrument and Control Engineers of Japan, SICE 2015, pp. 900-905, China, July 2015. 
[13] C. Chengqi, X. Wang, Q. Bin, K. Zhang, and L. Feng, "Coordinated Control of Vehicle Mounted Super Capacitor Energy Storage System and Inverter Feedback System," The Journal of New Industrialization, vol. 6, no. 10, pp. 10-14, 2016.

[14] X. Nian, F. Peng, and H. Zhang, "Regenerative braking system of electric vehicle driven by brushless DC motor," IEEE Transactions on Industrial Electronics, vol. 61, no. 10, pp. 5798-5808, 2014.

[15] E. H. El Brouji, O. Briat, J.-M. Vinassa, N. Bertrand, and E. Woirgard, "Impact of calendar life and cycling ageing on supercapacitor performance," IEEE Transactions on Vehicular Technology, vol. 58, no. 8, pp. 3917-3929, 2009. 


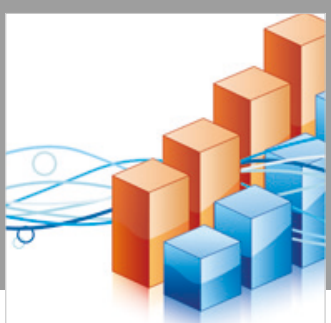

Advances in

Operations Research

\section{-n-m}
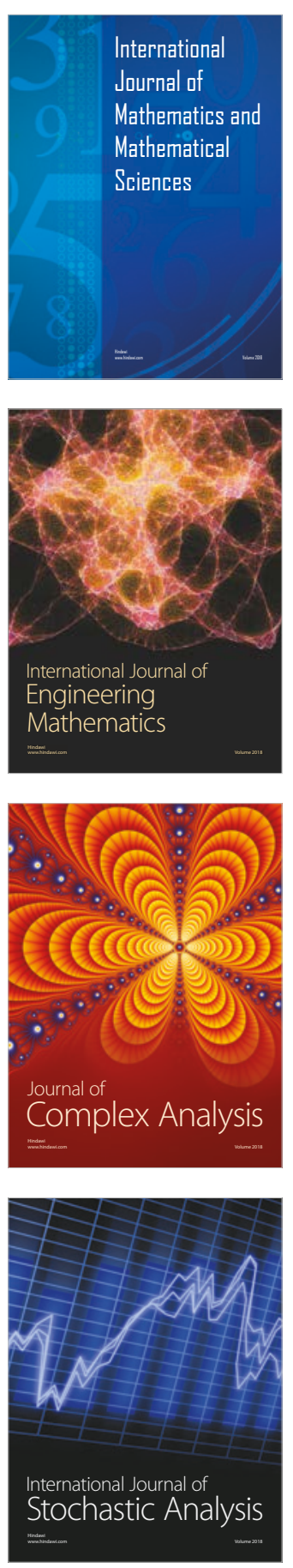
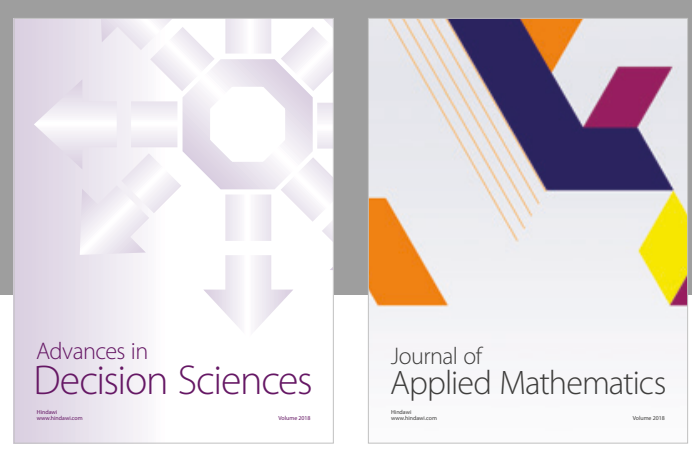

Journal of

Applied Mathematics
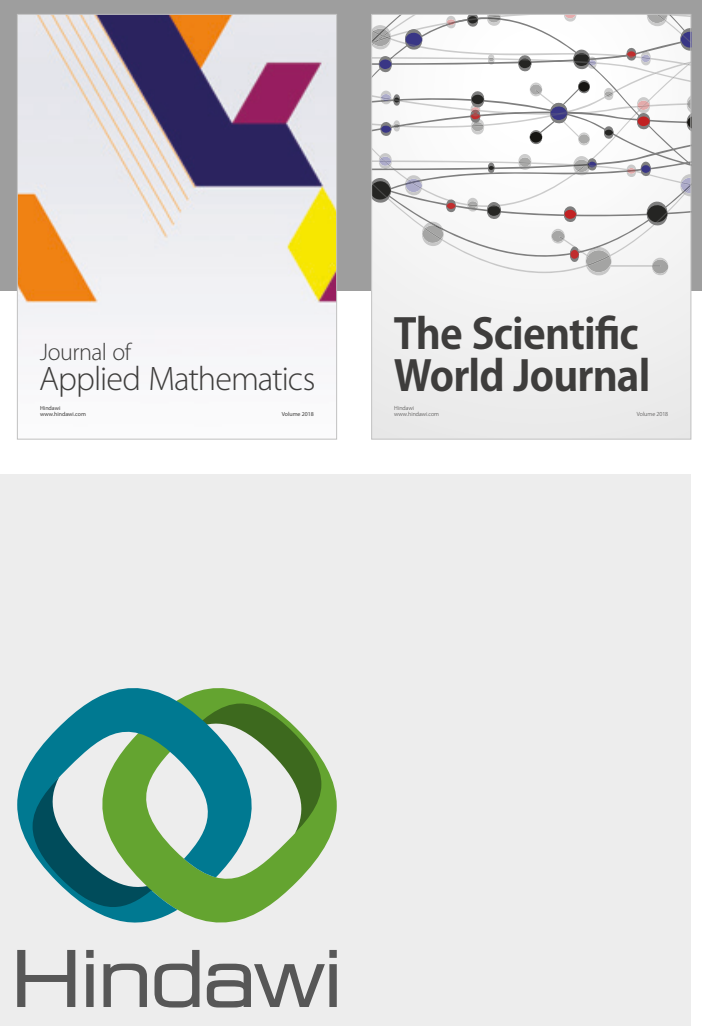

Submit your manuscripts at

www.hindawi.com

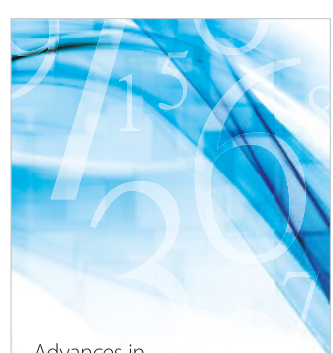

Advances in
Numerical Analysis
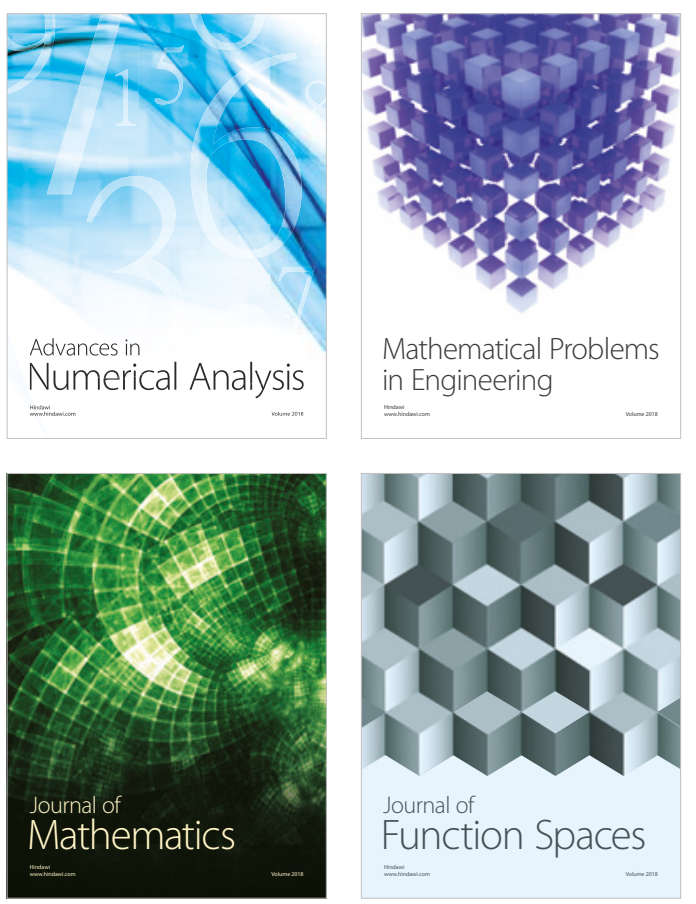

Mathematical Problems in Engineering

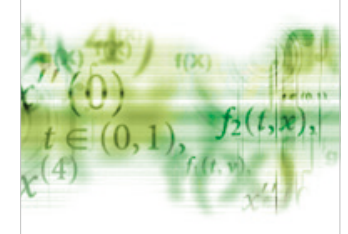

International Journal of

Differential Equations

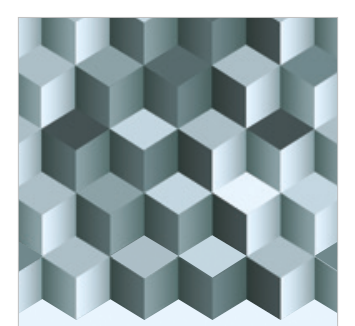

Journal of

Function Spaces

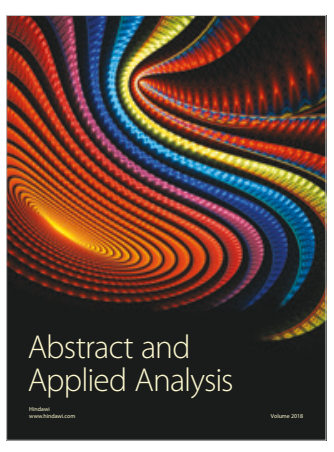

The Scientific

World Journal

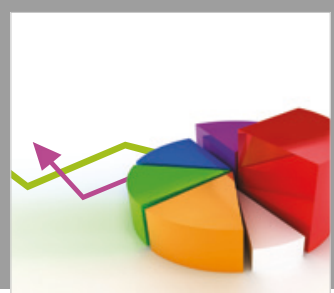

Journal of

Probability and Statistics
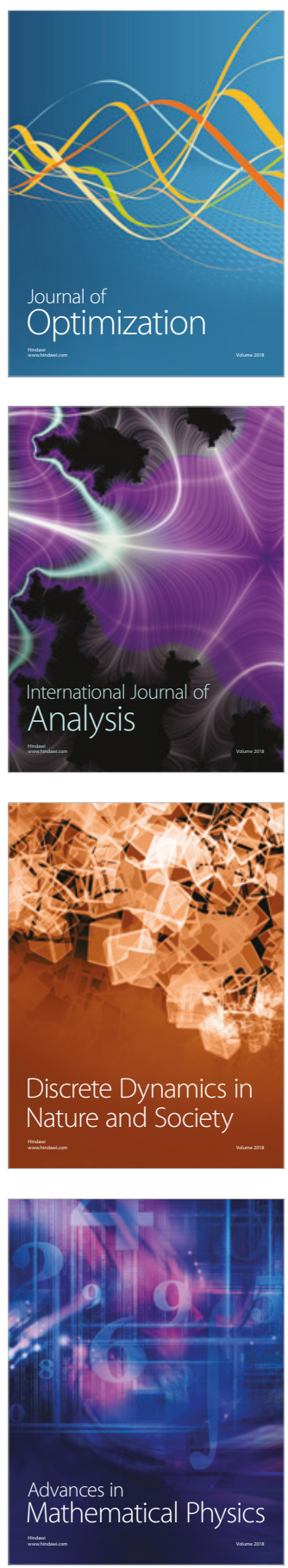